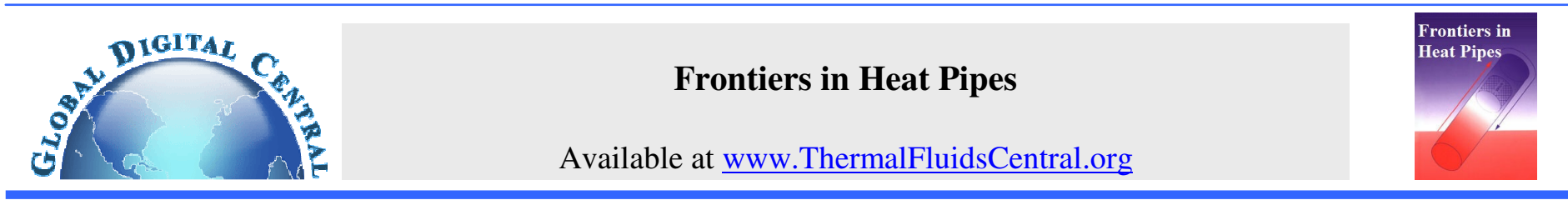

\title{
FLOW REGIME RECOGNITION IN TWO-PHASE THERMOSYPHON LOOPS USING PRESSURE PULSE ANALYSES
}

\author{
R.T. Dobson*, J.C. Ruppersberg \\ Department of Mechanical \& Mechatronic Engineering, University of Stellenbosch, Stellenbosch, 7602, South Africa
}

\begin{abstract}
The nuclear industry finds application for natural circulation in the form of passive heat removal systems used under accident conditions as well as for the removal of parasitic heat loss during normal operation. A high temperature gas-cooled reactor containment cooling system for instance can take the form of a series of closed-loop two-phase natural circulation thermosyphon type heat pipes. In this paper a means of remotely predicting the flow patterns in the two-phase regions of a closed loop heat pipe is proposed. The process involves the measurement of the working fluid pressure response in the single-phase flow region where safe access to the loop is possible from a nuclear radiation hazard point-of-view. The pressure signal is then decomposed and a frequency spectrum generated in order to find a characteristic frequency for each of the flow phenomenon observed. To establish the validity of the analytical method a $2.2 \mathrm{~m}$ high rectangular loop was built using $25 \mathrm{~mm}$ diameter copper pipe. Experiments were performed and a comparison of the frequency spectrums shows the ability of the proposed analytical method to correctly identify the presence of different flow patterns. It is thus provisionally concluded that the procedure as outlined in this paper can be used to remotely characterising the flow pattern associated with the different flow regimes in a closed loop two-phase thermosyphon-type heat pipe.
\end{abstract}

Keywords: Two-phase flow, Natural circulation loops, Signal analysis

\section{INTRODUCTION}

The concept of inherent safety is a fundamental part of the design philosophy of generation IV nuclear power reactors. In order to facilitate said safety philosophy, passive features are replacing active systems where possible. Passive features negate the need for machinery thereby reducing the risk of failure. This translates into an increase in system reliability whilst simultaneously reducing maintenance and operating costs.

It is the objective of this paper to show the application of this idea to the characterisation of a closed rectangular two-phase natural circulation loop. The pressure response of the system is measured in the single phase region of the loop rather than the two phase region, analysed and used to remotely predict the flow patterns in the twophase regions of the evaporator and condenser sections. The single phase region being specifically selected since it allows for safe access to the loop from a nuclear radiation hazard point-of-view.

In the following sections the operating modes of thermosyphon-type heat pipes will be defined and described, the experimental setup will be discussed, the signal processing process described, results given and conclusions drawn.

\section{BACKGROUND INFORMATION}

Comprehensive reviews of natural circulation systems are given by Greif (1988) and Zvirin (1981). More recently the IAEA compiled a technical document with a number of authors contributing papers on a range of topics involving natural circulation systems in the nuclear industry (Reyes and Cleveland, 2005).
Tujikura et al. (2000) describes the development of a pressurised water reactor design using a hybrid safety system employing both active and passive systems. Each system is responsible for a given set of accident conditions. In addition the passive system serves as backup in case the active system fails. This concept can be taken one step further by designing an entirely passive system. Dobson (2006) for instance proposes the use of a closed natural circulation loop for use as a reactor cavity cooling system in a high temperature gas cooled nuclear reactor. Such systems are self-regulating in as much as an additional heat input from the reactor causes a corresponding increase in heat transferred to the heat sink.

Depending on the system configuration and heat input, the operating mode may be either in the single phase or two-phase flow regions. Given two-phase flow operation several flow patterns are likely to be present, all differently affecting the thermo-flow characteristics of the system. A method of determining the various flow conditions would therefore be useful.

Ding et al. (2007) proposed a pressure analysis method. The differential pressure is measured across two pressure tappings in horizontal pipes of three sizes while liquid and gas flows through the pipes. Gas velocities are varied to cause various identifiable flow patterns. Subsequent analysis of the signal shows that different energy spectrums exist for each flow pattern thus making them identifiable via pressure measurement.

\section{OPERATING MODES AND THEORY}

This section defines and describes a number of concepts peculiar to the operation of thermosyphon loops, such as the one depicted in figure 1. Consider a rectangular loop of internal diameter $d$, length (height) $L$,

\footnotetext{
*Corresponding author: Email:rtd@sun.ac.za
} 
and width $W$, containing a working fluid and orientated in a vertical plane, relative to gravity, as shown in Fig.1. The loop may be operated at constant pressure using a relatively-large expansion tank maintained at a constant pressure $P$. The loop may be heated along the one vertical side and cooled along either the top horizontal side and/or the other vertical side, using tube-in-tube heat exchangers for instance. By introducing a temperature induced density gradient along the axial direction $z$ around the loop the less dense side of the loop will tend to rise and the more-dense sink, due to the effect of gravity (buoyancy). [Heating along the horizontal bottom side and cooling along the top side has to be avoided as then, at least in theory, there will be either no flow, flow from left to right or from right to left. If the top portion is heated and the lower portion cooled there will be no flow.

If the left hand side of the loop is exposed to a heat source and the right hand side to a heat sink the fluid in the loop will begin to circulate and heat will be transferred to the heat sink. If there is no noncondensable gas in the system when the heat is applied the fluid will begin to flow as a liquid; this single phase flow regime may be called the single phase operating mode. As more heat is supplied bubbles begin to form towards the top of the heated section; in the top horizontal section the flow stratifies, and the vapour ultimately condenses at the top of the cooled section in what is reminiscent of socalled annular two-phase flow; this condition might thus be called the two-phase operating mode. As more heat is added to the heating section the bubbly flow ceases to occur and a plug flow regime is established, and as even more heat is added, so-called churn flow occurs. These flow patterns shown in Figure 4. In two-phase operating mode there is always stratified flow pattern in the top horizontal pipe with a relatively smooth-surfaced liquid-vapour interface, however as the heat load increases transverse waves emanating from just before the bend down into the condensing section move back towards the heating section.

In two-phase operating mode liquid is pushed into the expansion tank. If however the displaced liquid is prevented from flowing from the expansion tank back into the loop (by means of a suitably positioned shutoff valve) a heat pipe operating mode may be defined for the loop. By placing a valve at the highest portion of the loop and

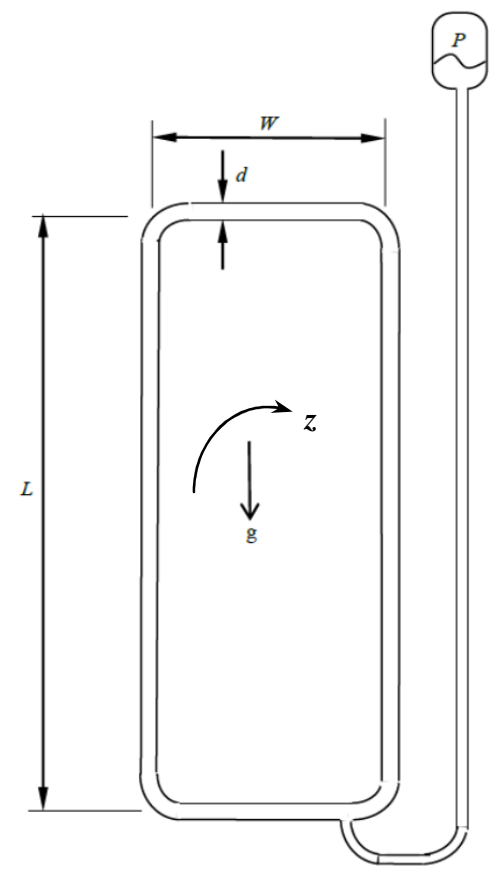

Fig. 1 Constant pressure closed loop natural circulation thermosyphon-type heat pipe while operating in two-phase mode non-condensable gas may be expelled (together with a little working fluid). This non-condensable blow-off procedure is often called "burping" and eliminates the need for a vacuum pump when charging the loop for heat pipe operation.

The flow and heat transfer behaviour of a thermosyphon-type heat pipe loop may be theoretically simulated by dividing the loop into a series of control volumes and applying the equations of change, namely mass, motion and energy, to each control volume and making use of say by way of example the homogeneous two-phase flow models (Dobson and ruppersberg, 2007). Such techniques work well with single and two-phase operating modes. In heat pipe operating mode the liquid level in the loop would typically be between one-third and one-half the height of the loop. For the heat pipe to function properly in this operating mode the working fluid must first start boiling. When boiling starts liquid is blasted up into the liquid deficient higher regions of the heating section reminiscent of the behaviour of a geyser. In this case simple one-dimensional two-phase theory cannot capture the geysering behaviour and the boiling and condensation heat transfer coefficients for the heating and cooling sections, respectively, need to be experimentally determined.

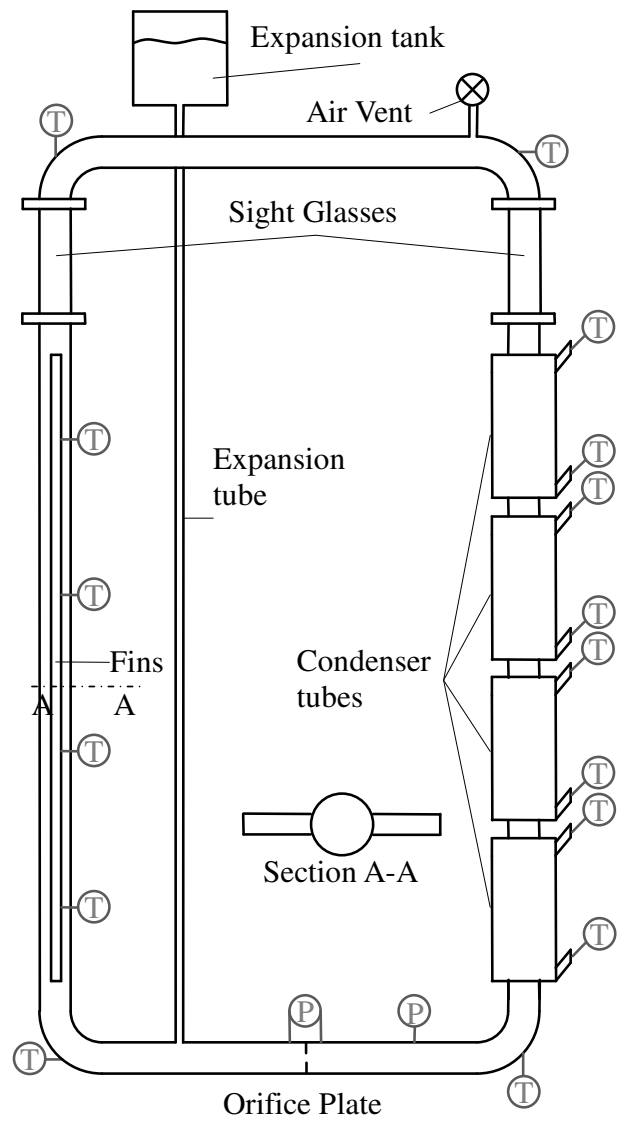

Fig. 2 Experimental closed loop thermosyphon

\section{EXPERIMENTAL SETUP}

A rectangular loop, $2.2 \mathrm{~m}$ high and $1 \mathrm{~m}$ wide, was built (see Fig. 2) using $25 \mathrm{~mm}$ inside diameter copper pipe with $0.22 \mathrm{~m}$ long sight glasses in the top of the evaporator and condenser sections of the loop. The working fluid of preference was water, chosen for availability, ease of use and low cost. An expansion tank was connected to the loop to allow the working fluid to contract and expand during the heating cycle. Heating elements were attached to the fins welded along the length of the evaporator tube. The input power was variable with an upper limit of $2 \mathrm{~kW}$. Cooling was provided by tube-in-tube heat 
exchangers arranged along the length of the condenser tube. The cooling heat exchanger fluid was water delivered from a constant header tank at ambient temperatures.

Sensors were installed to measure both pressure and temperature at various points in the loop. The temperatures of the fins, working fluid and condenser fluid were measured with K-type thermocouples. The wall pressure in the single phase region was measured with a PCB 108A02 piezoelectric pressure transducer. Mass flow rate measurements across the orifice were performed with the aid of an Endress-Hauser PMD75 differential pressure transducer.

The signal from the PCB transducers were logged using a National Instruments NI cDAQ-9172 data logger while the thermocouple and differential pressure transducer signals were logged with a 34970A Agilent data logger. The power settings and condenser flow rates could be varied to generate data sets for comparison over a range of input conditions.

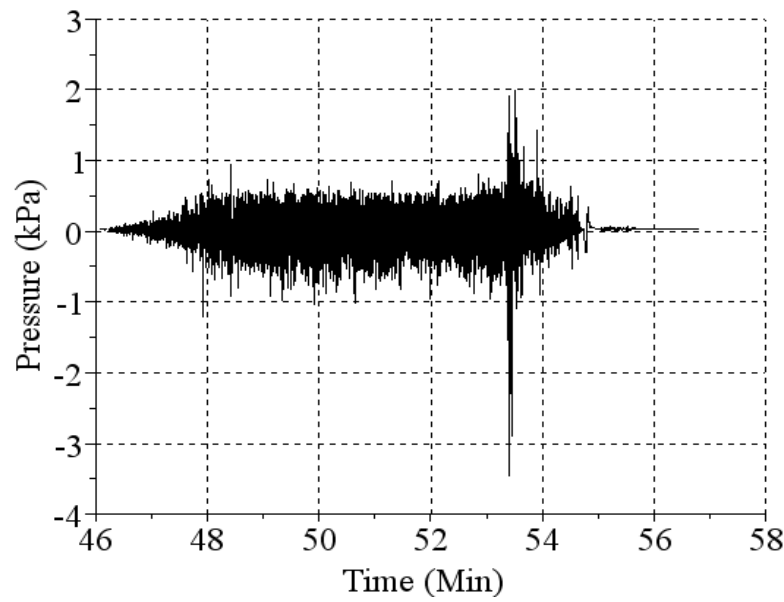

Fig. 3 Typical pressure signal as a result of two-phase (as recorded in single phase region)

\section{SIGNAL PROCESSING}

Due to the nature of two phase flow the measured pressure response signal is both nonlinear and non-stationary (frequency changes with time). A literature review showed the analysis method of Huang et al. (1998) to be applicable. This decomposition method is based on the local characteristic time scale of the signal, adapting the base functions rather than simply assuming sinusoidal functions thus allowing for the determination of a meaningful frequency spectrum. The method has been successfully applied by several authors for example Ding et al. (2007) in horizontal two-phase flow, Yang (2008) in the vibrations analysis of exhaust valves in an internal combustion engine and Ong et al. (2007) in structural vibration monitoring.

The Hilbert-Huang transformation method was applied to the experimental data sets and resulted in a range of frequencies being identified for each of the flow regimes. This was due to certain limitations associated with the decomposition method. The main limitation was the inability of the method to decompose the signal into mono-component functions under certain circumstances. These limitations have been addressed in literature by a number of authors, each proposing a method that adapts the original method to overcome the limitations. Among these the method of Ong et al. (2008) was chosen since it does not require prior knowledge of the frequencies under investigation, in contrast to many of the other proposed methods. The method involves the use of digital filtering prior to the use of the Hilbert-Huang transform resulting in a clearly defined frequency spectrum. For each experiment Ong's procedure was followed and a spectrum generated in order to find characteristic frequencies for each of the flow phenomenon observed.

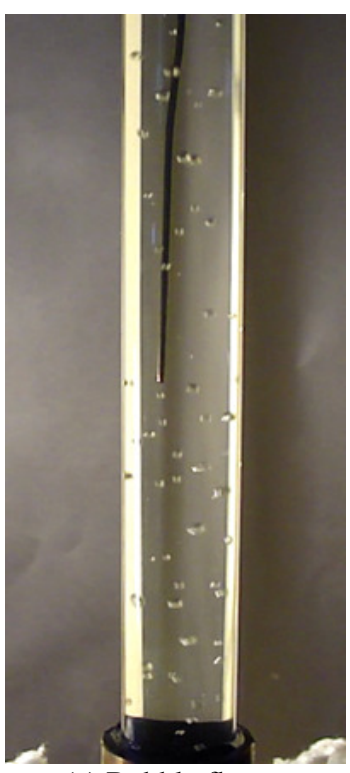

(a) Bubbly flow

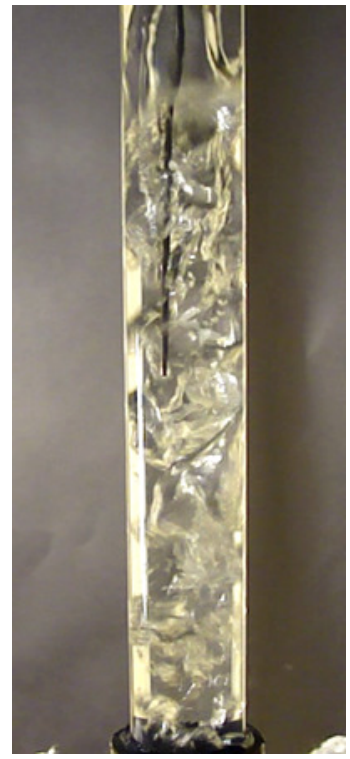

(c) Churn flow

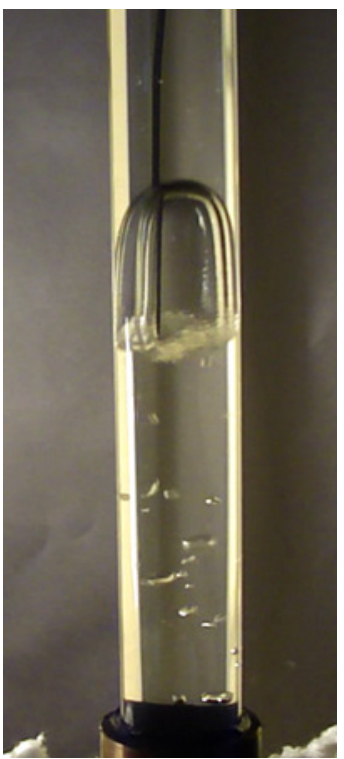

(b) Plug flow
Fig. 4 Selected flow patterns (as observed)

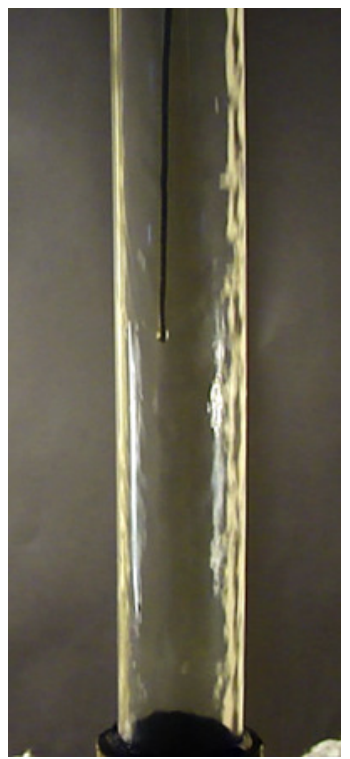

(d) Annular flow

\section{RESULTS AND DISCUSSION}

In a previous paper by Dobson and Ruppersberg (2010) the pressure signal was evaluated using alternative pressure transducers and produced the following results. The bubble flow regime showed a frequency of $0.5-0.6 \mathrm{~Hz}$, the churn flow regime a frequency of $0.2 \mathrm{~Hz}$ and the plug flow regime a frequency of $0.14 \mathrm{~Hz}$. The frequencies presented were very low. It was concluded that the transducer measured the oscillating static pressure in the lower leg of the loop. The oscillations being caused by the filling and draining of the relatively small sized expansion tank, which was dependent on the amount of vapour present in the loop, which in turn depended on the flow pattern present.

In order to find the frequencies directly linked to the flow patterns, rather than through the expansion tank, pressure transducers capable of a higher sampling frequency were installed. Fig. 3 shows the measured wall pressure signal for a single heating and cooling cycle in a single experiment using the PCB transducer. 


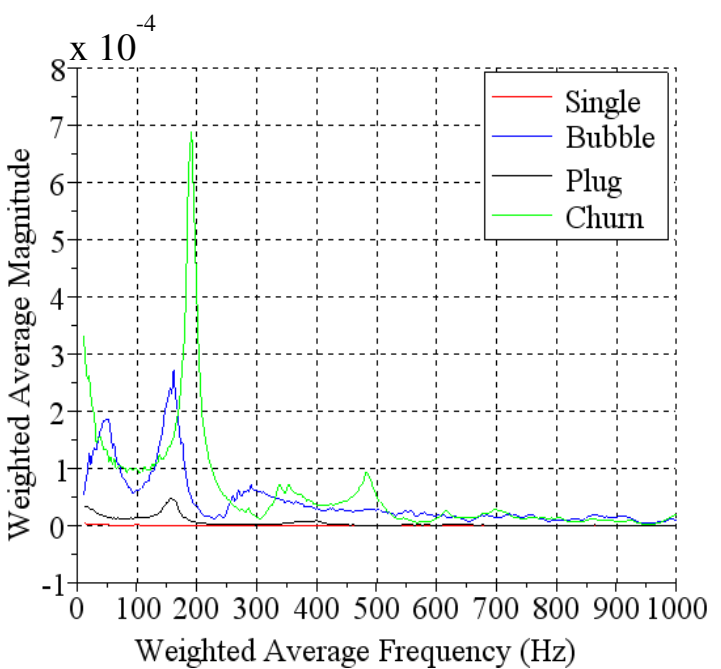

Fig. 5 Typical weighted average magnitude as a function of the weighted frequency for single phase, bubble, plug and churn flow patterns

During each thermal cycle the loop operated in the single phase region, transitioned to the two-phase region and back again. Figure 4 shows the examples of the flow patterns as typically observed through the evaporator sight glass. On the opposite side of the loop the general flow pattern in the condenser section was more-or-less characterised by annular flow independent of whether the flow was bubbly, plug, churn or turbulent in the evaporator section.

At the onset of the experiments it was unclear what frequency range would apply to the flow regimes. The logging was performed at the maximum rate of the transducer which was $25 \mathrm{kHz}$. In post processing, the data could be reduced to the most appropriate sampling rate. The signal analysis method requires an upper and lower boundary within which the characteristic frequency may be found. The boundaries were set to between $10 \mathrm{~Hz}$ and $3000 \mathrm{~Hz}$. This range was broad enough to capture the characteristic frequencies without being overly computationally expensive.

Fig. 5 shows the frequency spectrum generated. Four lines are shown corresponding to the flow patterns present. Each line was produced by applying the analysis method to the pressure signal corresponding to the time period recorded during visual observation of a given flow pattern.

The line with no significant peaks (line just above zero amplitude) indicates the single phase flow region that had scant influence on the pressure signal. Bubble flow shows two distinct peaks at $50 \mathrm{~Hz}$ and $160 \mathrm{~Hz}$ and a minor peak at $300 \mathrm{~Hz}$ while plug flow has its main peak at $170 \mathrm{~Hz}$ with a minor peak at $400 \mathrm{~Hz}$ and churn flow has its main peak at $187 \mathrm{~Hz}$ with two more minor peaks at $350 \mathrm{~Hz}$ and $485 \mathrm{~Hz}$. (The peak at $50 \mathrm{~Hz}$ was due to improper grounding of the $50 \mathrm{~Hz}$ electrical power frequency.

In addition to the characteristic frequencies that were found it can also be seen that each of the flow patterns produced significantly different weighted average magnitudes thus enhancing the method's ability to differentiate between the flow patterns.

These results are reproduced in Fig, 6 showing each of the flow patterns individually but with additional results from two more different experiments added for the sake of comparison, and thereby showing a reasonable degree of repeatability using this method. The results indicate the presence of distinct frequencies for each of the different flow patterns. This is however only the first step, several questions remain. What physical phenomena can explain the frequency values? Are these frequencies geometry dependant? What is the influence of flow obstructions? Does the working fluid have an influence on the results? Will signal attenuation play a role in larger loops?

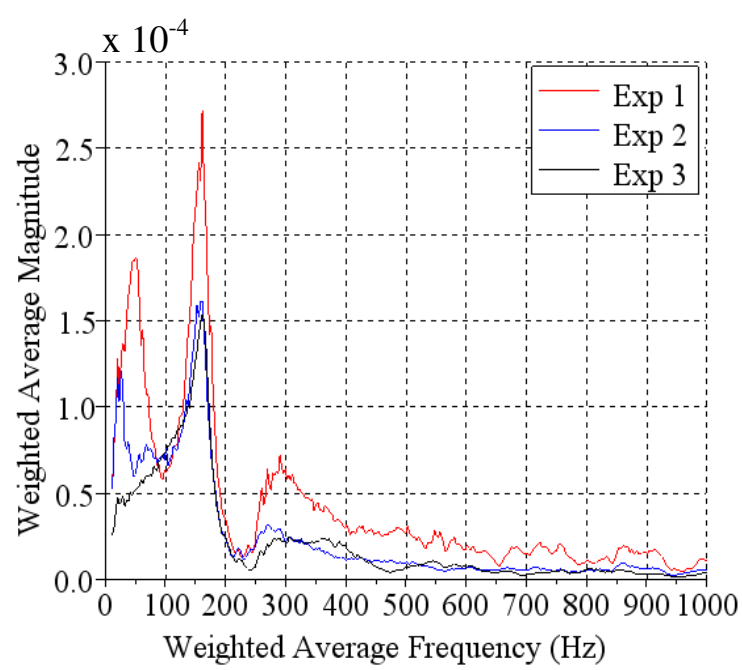

(a) Bubble flow
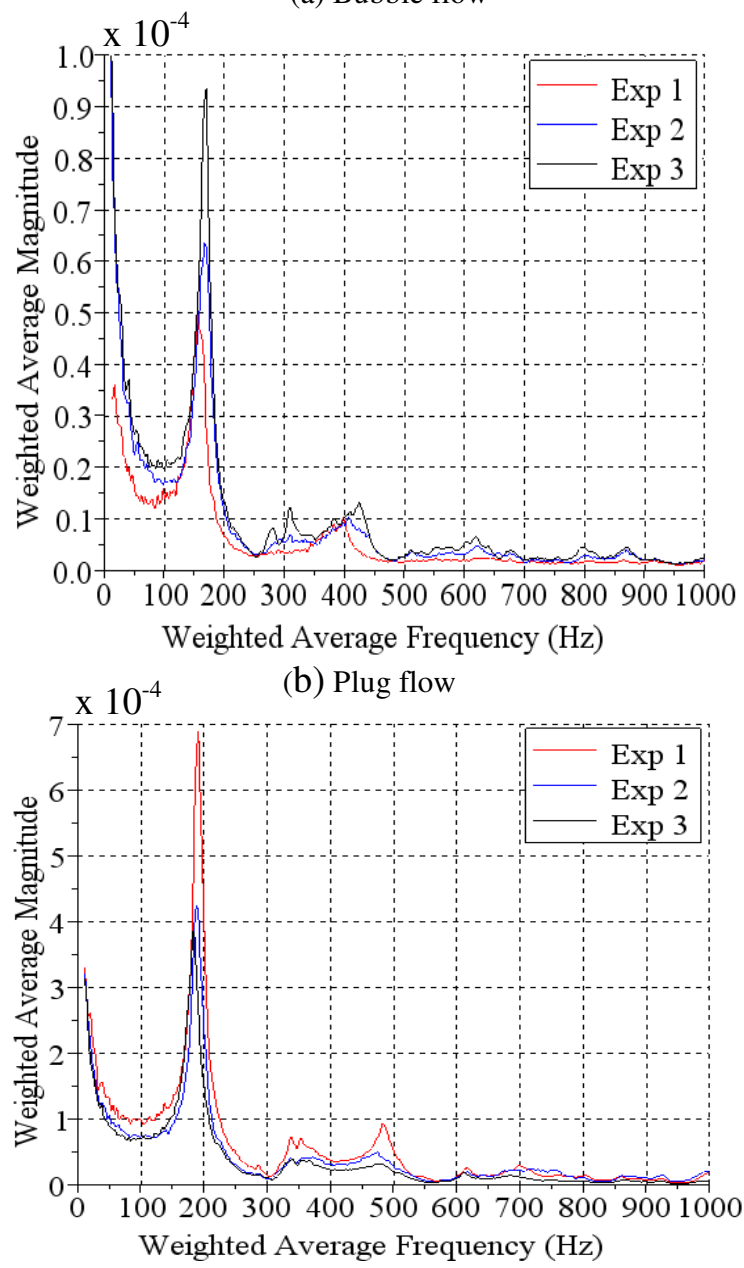

(c) Churn flow

Fig. 6 Weighted average magnitude as a function of the weighted frequency for (a) bubble, (b) plug and (c) churn flow patterns 


\section{CONCLUSIONS}

A means of remotely predicting the flow patterns in the two-phase regions of a closed loop heat pipe system applicable to the cooling of a HTGR citadel was proposed.

The pressure response in the single-phase working fluid was measured experimentally and a representative data set was presented. For signal analysis the local and adaptive method of Huang et al. (1998) with the proposed improvements of Ong et al. (2008) was chosen, described and successfully applied.

Characteristic frequencies for three different flow regimes were determined as present in a $2 \mathrm{~m}$ high rectangular closed copper loop. The main frequencies are $160 \mathrm{~Hz}$ for bubble flow, $170 \mathrm{~Hz}$ for plug flow and $187 \mathrm{~Hz}$ for churn flow.

The influence of various parameters on the specific frequencies is as yet unclear and will be investigated in future. To this end a second $8 \mathrm{~m}$ loop has been constructed and a third $26 \mathrm{~m}$ loop is under construction.

The viability of the adapted analytical procedure as outlined in this paper for the remote characterisation of the pressure pulse to identify the different flow regimes in a rectangular closed loop two-phase thermosyphon-type heat pipe has been provisionally proven.

\section{ACKNOWLEDGEMENT}

The authors would like to thank PBMR Pty LTD and the South African for their support.

\section{NOMENCLATURE}

$\begin{array}{ll}d & \text { diameter }(\mathrm{m}) \\ \mathrm{g} & \text { acceleration due to gravity }\left(\mathrm{m}^{2} / \mathrm{s}\right) \\ L & \text { length, height }(\mathrm{m}) \\ P & \text { Pressure }(\mathrm{Pa}) \\ W & \text { width }(\mathrm{m}) \\ z & \text { axial direction }\end{array}$

\section{REFERENCES}

Ding, H., Huang, Z., Song, Z., and Yan, Y., 2007, "Hilbert-Huang Transform Based Signal Analysis for the Characterization of Gas-liquid Two-phase Flow," Flow Measurement and Instrumentation, 18, 37-36. http://dx.doi.org/10.1016/j.flowmeasinst.2006.12.004

Dobson, R.T., 2006, “A Novel Closed Loop Thermosyphon Heat Pipe Reactor Cavity Cooling System for a Pebble Bed Modular Reactor,"
Proceedings of the 8th International Heat Pipe Symposium, 24-27 Sept., 2006, Kumamoto, 384-397.

Dobson, R.T., and Ruppersberg, JC, 2010, “A Pressure Pulse Analysis Method to Characterise the Flow Patterns in a Two-Phase Closed-loop Natural Circulation Thermosyphon-type Heat Pipe," Proceedings of the 15th International Heat Pipe Conference, 25-30 Apr. 2010, Clemson..

Greif, R., 1988, "Natural Circulation Loops," Journal of Heat Transfer, $110,1243-1257$. http://dx.doi.org/10.1115/1.3250624

Huang, N.E., Shen, Z., Long, S.R., Wu, M.C., Shih, H.H., Zheng, Q., Yen, N.C., Tung, C.C., and Liu, H.H, 1998, "The Empirical Mode Decomposition and the Hilbert Spectrum for Nonlinear and Nonstationary Time Series Analysis," Proceedings of the Royal Society London Series A, 454, 903-995. http://dx.doi.org/10.1098/rspa.1998.0193

Ong, K.C.G., Wang, Z., and Maalej, M., 2008, "Adaptive magnitude spectrum algorithm for Hilbert-Huang transform based frequency identification”, Engineering Structures, 30, 33-41. http://dx.doi.org/10.1016/j.engstruct.2007.02.018

Reyes, J., and Cleveland, J., 2005, "Natural Circulation in Water Cooled Nuclear Power Plants, Phenomena, Models and Methodology for System Reliability Assessments," IAEA TECDOC, 1-51.

Ruppersberg, J.C. and Dobson, R.T., 2007, "Flow and Heat Transfer in a Closed Loop Thermosyphon Part I - Theoretical Simulation," Journal of Energy in Southern Africa, 18(4), 32-40.

Ruppersberg, J.C., and Dobson, R.T., 2007, "Flow and Heat Transfer in a Closed Loop Thermosyphon Part II - Experimental Simulation," Journal of Energy in Southern Africa, 18(4), 31-48.

Tujikura, Y., Oshibe, T., Kijima, K., and Tabuchi, K., 2000, "Development of Passive Safety Systems for Next-generation PWR in Japan," Nuclear Engineering and Design, 201, 61-70. http://dx.doi.org/10.1016/S0029-5493(00)00261-2

Yang, W.X., 2008, "Interpretation of Mechanical Signals using an Improved Hilbert-Huang Transform," Mechanical Systems and Signal Processing, 22, 1061-1071. http://dx.doi.org/10.1016/j.ymssp.2007.11.024

Zvirin, Y., 1981, "A review of Natural Circulation Loops in Pressurized Water Reactors and other Systems," Nuclear Engineering and Design, 67, 203-225.

http://dx.doi.org/10.1016/0029-5493(82)90142-X 